\title{
Modulation of the intrinsic neuronal excitability by multifunctional liposomes tailored for the treatment of Alzheimer's disease
}

This article was published in the following Dove Press journal:

International Journal of Nanomedicine

\author{
Anna Binda' \\ Alice Panariti ${ }^{1}$ \\ Andrea Barbuti ${ }^{2}$ \\ Carmen Murano' \\ Roberta Dal Magro' \\ Massimo Masserini ${ }^{1,3,4}$ \\ Francesca $\mathrm{Re}^{1,3,4}$ \\ Ilaria Rivolta ${ }^{1,3,4}$ \\ 'School of Medicine and Surgery, \\ University of Milano-Bicocca, Monza, \\ Italy; ${ }^{2}$ Department of Biosciences, \\ The PaceLab and Interuniversity \\ Center of Molecular Medicine and \\ Applied Biophysics (CIMMBA), \\ University of Milan, Milano, Italy; \\ ${ }_{3}^{3}$ Milan Center for Neuroscience \\ (NeuroMI), University of Milano- \\ Bicocca, Monza, Italy; ${ }^{4}$ Nanomedicine \\ Center NANOMIB, University of \\ Milano-Bicocca, Milano, Italy
}

Correspondence: llaria Rivolta School of Medicine and Surgery, University of Milano-Bicocca, Via Cadore 48, 20900 Monza, Italy

Tel +390264488319

Fax +390264488068

Email ilaria.rivolta@unimib.it
Purpose: Nanotechnologies turned out to be promising in the development of diagnostic and therapeutic approaches toward neurodegenerative disorders. However, only a very scant number of nanodevices until now proved to be effective on preclinical animal models. Although specific tests in vivo are available to assess the potential toxicity of these nanodevices on cognitive functions, those to evaluate their biosafety in vitro on neurons are still to be improved.

Materials and methods: We utilized the patch-clamp technique on primary cultures of cortical neural cells isolated from neonatal rats, aiming to evaluate their electrical properties after the incubation with liposomes (mApoE-PA-LIPs), previously proved able to cross the blood-brain barrier and to be effective on mouse models of Alzheimer's disease (AD), both in the absence and in the presence of $\beta$-amyloid peptide oligomers.

Results: Data show a high degree of biocompatibility, evaluated by lactate dehydrogenase (LDH) release and MTT assay, and the lack of cellular internalization. After the incubation with mApoE-PA-LIPs, neuronal membranes show an increase in the input resistance (from $724.14 \pm 76 \mathrm{M} \Omega$ in untreated population to $886.06 \pm 86 \mathrm{M} \Omega$ in the treated one), a reduction in the rheobase current (from $29.6 \pm 3$ to $24.2 \pm 3 \mathrm{pA}$ in untreated and treated, respectively), and an increase of the firing frequency, consistent with an ultimate increase in intrinsic excitability. Data obtained after co-incubation of mApoE-PA-LIPs with $\beta$-amyloid peptide oligomers suggest a retention of liposome efficacy.

Conclusion: These data suggest the ability of liposomes to modulate neuronal electrical properties and are compatible with the previously demonstrated amelioration of cognitive functions induced by treatment of $\mathrm{AD}$ mice with liposomes. We conclude that this electrophysiological approach could represent a useful tool for nanomedicine to evaluate the effect of nanoparticles on intrinsic neuronal excitability.

Keywords: neurodegenerative disorders, nanomedicine, action potential, electrophysiology, patch clamp, $\beta$-amyloid peptide

\section{Introduction}

Alzheimer's disease (AD) is one of the most studied and worldwide common neurodegenerative disorders. As such, AD has the clinical feature of a selective and progressive loss of neuronal cells, which is responsible for the typical behavioral and physical deficits. There are many different pathological events happening in the brain, such as accumulation of the $\beta$-amyloid peptide $(A \beta)$, presence of neurofibrillary tangles of the microtubule-associated hyper-phosphorylated protein tau, neuronal and synaptic loss, cerebral atrophy, and signs of inflammation. Among these events, researchers suggest that the generation of the neurotoxic $A \beta$ peptide from sequential amyloid 
precursor protein (APP) proteolysis is the crucial step in the development of $\mathrm{AD}$.

So far, current different therapeutic strategies for AD offer modest and short-term benefits. Nanotechnologies, which consist in the research of tools and systems through the nanometric control of the material, ${ }^{1}$ are very promising in the development of both diagnostic and therapeutic approaches for neurodegenerative diseases.

Among the reasons, nanocarriers could be functionalized in order to have the ability to cross the blood-brain barrier (BBB), improving both qualitatively and quantitatively the transport of drugs directed to the central nervous system (CNS), and limiting, at the same time, side effects. In recent years, our group developed multifunctional nanoliposomes, composed of sphingomyelin ( $\mathrm{Sm}$ ) and cholesterol (Chol) and bifunctionalized with phosphatidic acid (PA) and with a peptide (mApoE) derived from the receptor-binding domain of apolipoprotein E (named mApoE-PA-LIPs) as a candidate for the treatment of AD. ${ }^{2-4}$ The presence of PA has been shown to confer to LIPs strong affinity for $A \beta$ in different aggregation forms; mApoE-derived molecules, instead, improve the passage of nanoliposomes across the BBB either in vitro or in vivo. ${ }^{5}$

In vivo studies on mouse model of $\mathrm{AD}$ demonstrated that mApoE-PA-LIPs cross the BBB and showed the efficacy to recover long-term recognition memory and to reduce the number and total area of $A \beta$ plaques in the brain. ${ }^{6}$ These same nanoliposomes have been confirmed to prevent memory loss in a presymptomatic mouse model of $\mathrm{AD}$ as well. ${ }^{7}$

The mechanism of action responsible for these improvements could be inferred by the results obtained in vitro: $\mathrm{mApoE}-$ PA-LIPs were able to bind to $A \beta$ with high affinity, to inhibit the formation, and to destabilize the preformed accumulation of $\mathrm{A} \beta_{1-42}$ aggregates without affecting either endothelial and neuroblastoma cells' viability or the BBB monolayer integrity. Moreover, they were internalized by cells, likely by a receptormediated endocytosis and transported in their intact form across the monolayer of hCMEC/D3, a model of BBB. ${ }^{3}$

Eventually, mApoE-PA-LIPs possess the capacity to sequester $A \beta_{1-42}$ in human plasma and cerebrospinal fluid ${ }^{4}$ endorsing the hypothesis of the "sink effect" supported by the in vivo data related to the increment of $A \beta$ in the liver and in the spleen in AD mice treated with mApoE-PA-LIPs. ${ }^{6}$

However, nanoparticles (NPs) used as therapeutic tool cannot be considered as an inert delivery vehicle. ${ }^{8}$ Even though liposomes (LIPs) are considered to be more biocompatible with respect to other NPs, it has been reported that amine-modified polystyrene NPs or gold NPs change the membrane cellular potential in non-excitable cells upon binding, not by acting as permeabilizing agent, but by interfering with potassium channels responsible for the maintenance of the resting potential. ${ }^{9}$ In plant cells, silver NPs were responsible for an increase of intracellular calcium concentration that was prevented by the application of $\mathrm{Gd}^{3+}$, a calcium channel blocker; moreover, they inhibited potassium outward current as well. ${ }^{10}$

Since mApoE-PA-LIPs have been developed as a therapeutic tool for $\mathrm{AD}$ and are able to cross the $\mathrm{BBB}$, attention has to be payed to their possible adverse effects. The in vivo data obtained on transgenic mice exposed to mApoE-PA-LIPs suggest that no apparent acute toxicity effect is exerted on the brain, at least under the experimental conditions adopted. Nevertheless, neurons are likely the most delicate cells of the body; thus, the possible effects on the physiological activity of excitable cells of the CNS have to be still thoroughly investigated. Indeed, the environment beyond the barrier is rich in neurons, whose electrophysiological properties should be preserved in order to maintain their electrical activity. Therefore, in this study, we evaluated the effects of mApoE-PA-LIPs on the excitable properties of primary culture of cortical neurons isolated from neonatal rats. Moreover, due to the difficulties of obtaining single neuronal cells from adult mice model of $\mathrm{AD}$, we mimicked the in vivo condition incubating cortical neurons with $A \beta$ oligomers and investigated whether $\mathrm{mApoE}-$ PA-LIPs retained the ability to exert their effect.

\section{Materials and methods Primary cell culture}

All procedures involving animals and their care were conducted according to European and Italian laws and policies (D. Lgs. no 2014/26, 2010/63/UE) and approved by the University of Bicocca Animal Care and Use Committee that includes ad hoc members for ethical issues. Primary cultures of cortical neural cells were isolated from neonatal rats (Charles River), 3 days postbirth (P3), ${ }^{11}$ and cultured for 6 or 7 days (DIV6-7) in $\mathrm{p} 35$ dishes coated with poly-L-lysine in a controlled environment $\left(5 \% \mathrm{CO}_{2}, 37^{\circ} \mathrm{C}\right)$ in Neurobasal A culture medium (Thermo Fisher Scientific, Waltham, MA, USA) supplemented with B27 (Thermo Fisher Scientific), glutamine ( $1 \mathrm{mM}$; Thermo Fisher Scientific), $\beta$-FGF (10 ng/mL; Thermo Fisher Scientific), penicillin $\mathrm{G}(50 \mathrm{U} / \mathrm{mL})$ and streptomycin (50 $\mu \mathrm{g} / \mathrm{mL}$; Thermo Fisher Scientific). The culture contained both neurons and non-neuronal cells, such as astrocytes as the experiments of immunofluorescence proved.

The authors confirm that all the mandatory health and safety procedures have been complied with in the course 
of conducting any experimental work reported in the present paper.

\section{Preparation and characterization of multifunctional LIPs}

LIPs, designed for Alzheimer's treatment, were prepared and characterized as previously described. ${ }^{12,13}$ Briefly, LIPs were composed of a matrix of Sm and Chol (1:1 molar ratio), prepared by extrusion procedure and functionalized with $\mathrm{PA}$, as $A \beta$-binding agent, and with a modified peptide (mApoE) derived from the receptor-binding domain of apolipoprotein $\mathrm{E}$, as BBB target ligand. These multifunctional LIPs are dubbed as mApoE-PA-LIPs.

For immunofluorescence experiments, fluorescent $\mathrm{mApoE}$ PA-LIPs, carrying BODIPY-FL C12-Sm (Thermo Fisher Scientific) in the lipid bilayer, were used. The fluorescent probe $(0.5 \%$ mol of total lipids) was added to the lipid mixture before the extrusion procedure. To remove un-incorporated material, LIPs were diafiltered through 30,000 molecular weight (MW) cutoff membrane, as described. ${ }^{6}$ The yield of fluorescent probe incorporation and surface functionalization with $\mathrm{mApoE}$ peptide was determined by spectrofluorometric analysis. The total lipid recovery was measured by Stewart's assay. Size and polydispersity index (PDI) were analyzed by dynamic light scattering (DLS) technique (Brookhaven Instruments Corporation, NY, USA). $\zeta$-potential was determined by using an interferometic Doppler velocimetry with the same instrument equipped with ZetaPALS device.

\section{Preparation of $A \beta$ oligomers}

$\mathrm{A} \beta$ oligomers were prepared as previously described., ${ }^{3,14}$ Briefly, $A \beta_{1-42}$ (Sigma-Aldrich Co., St Louis, MO, USA) lyophilized peptide was solubilized in 1,1,3,3,3-hexafluoro2-propanol (HFIP, Sigma-Aldrich Co) at $1 \mathrm{mg} / \mathrm{mL}$ concentration. The peptide was allowed to air dry in a chemical fume hood overnight and suspended in dimethyl sulfoxide (DMSO; Sigma-Aldrich Co) in order to obtain a peptide concentration of $5 \mathrm{mM}$. After bath sonication of $10 \mathrm{~min}$, the sample was diluted to $100 \mu \mathrm{M}$ in phosphate-buffered solution (PBS) and incubated $24 \mathrm{~h}$ at $4{ }^{\circ} \mathrm{C}$ to obtain an oligomer-enriched preparation. The formation of oligomers was assessed by atomic force microscopy as described. ${ }^{3,14}$

\section{Effect of treatment with multifunctional LIPs on cell viability}

Cortical neural cells were plated on 96 wells at a density of 5,000 cells/well and kept in a controlled environment $\left(37^{\circ} \mathrm{C}\right.$ and $5 \% \mathrm{CO}_{2}$ ). At DIV6, cells were exposed for 4 or $48 \mathrm{~h}$ to the medium containing mApoE-PA-LIPs at a concentration of $10 \mu \mathrm{M}$. This dose was chosen based on in vivo studies as the concentration of NPs able to reach the brain. ${ }^{3,6}$ The effect of treatment with LIPs on cells' viability was assessed by measuring the lactate dehydrogenase (LDH) release (LDH Cytotoxicity Detection KitPLUS; Hoffman-La Roche Ltd., Basel, Switzerland) and by measuring the mitochondrial enzymatic activity by MTT assay (MTT Formazan; SigmaAldrich Co.), as previously described. ${ }^{15}$ Untreated cells were used as negative control. For the LDH assay, cells lysed with a specific buffer in order to free the whole cellular LDH were used as positive control, whereas for the MTT assay, the positive control is not required.

\section{Cellular uptake of LIPs by immunofluorescence}

Cells were seeded on glass coverslips. At the end of incubation (1, 4 or $24 \mathrm{~h}$ ) with $10 \mu \mathrm{M}$ of fluorescent labeled mApoE-PA-LIPs, neural cultures were fixed with paraformaldehyde (PFA), washed three times with protein-free PBS and incubated with anti- $\beta$ III Tubulin antibody (1:250; Promega Corporation, Fitchburg, WI, USA) or with glial fibrillary acidic protein (GFAP) antibody (1:400; Sigma-Aldrich $\mathrm{Co}$ ) for $2 \mathrm{~h}$ at room temperature and, after washes, with Alexa Fluor 594-conjugated goat anti-mouse IgG (1:100; Thermo Fisher Scientific) for $1 \mathrm{~h}$ at room temperature. $1 \mu \mathrm{M}$ DAPI (Sigma-Aldrich Co) was used to label nuclei. Images were acquired with LSM710 inverted confocal laser scanning microscope equipped with a Plan-Neofluar $63 \times 1.4$ oil objective (Carl Zeis Meditec AG, Jena, Germany). Excitation wavelengths were $\lambda=488 \mathrm{~nm}$ to detect LIPs, $\lambda=610 \mathrm{~nm}$ to detect $\beta$ III Tubulin or GFAP, and $\lambda=405 \mathrm{~nm}$ to detect nuclei.

\section{LIPs-cells interaction by fluorescence imaging of live cells}

Cells were seeded on glass coverslips. After 1 or 4 hours of incubation with fluorescent-labeled mApoE-PA-LIPs, neuronal cultures were washed once and medium was substituted with the extracellular solution used for electrophysiological recordings. Images were acquired with the LSM710 inverted confocal laser scanning microscope equipped with a Plan-Neofluar $63 \times 1.4$ oil objective (Carl Zeiss Meditec AG). $\lambda=488 \mathrm{~nm}$ and bright field were used to detect LIPs and cells, respectively. The quantitative analysis of the green signal (mApoE-PA-LIPs) was performed using ImageJ software (Image J, U. S. National Institutes of Health, Bethesda, MD, USA). 


\section{Electrophysiological recordings}

Recordings on primary cortical neurons were done at room temperature $\left(22^{\circ} \mathrm{C}-25^{\circ} \mathrm{C}\right)$ applying the patch-clamp technique in the whole-cell configuration. The set-up was equipped with a Multiclamp 700B patch-clamp amplifier, a Digidata 1440A (both from Axon Instruments, Molecular Device, Sunnyvale, CA, USA), and pClamp 10.3 software (Molecular Devices LLC, Sunnyvale, CA, USA).

The cell capacitance and the resting membrane potential were measured immediately after obtaining the whole-cell configuration. The input resistance was calculated according to Ohm's law.

After the measurement of the passive properties in voltageclamp mode, the amplifier was then switched to current-clamp mode, the bridge balance compensation was applied, and the membrane resting potential was held at $-70 \mathrm{mV}$ by injecting the appropriate current. Neuronal firing was generated injecting $1 \mathrm{~s}$-long depolarizing current pulses of increasing amplitude in $10 \mathrm{pA}$ steps. The minimum current necessary to elicit an action potential (AP; the so-called rheobase current) and the frequency of APs were then measured.

The internal pipette solution contained the following (in $\mathrm{mM}$ ): $120 \mathrm{~K}$-gluconate, $15 \mathrm{KCl}, 2 \mathrm{MgCl}_{2}, 0.2$ EGTA, 20 phosphocreatine-Tris, 2 ATP-Na $2,0.2$ GTP-Na, 0.1 leupeptin, and $10 \mathrm{~K}-\mathrm{HEPES}, \mathrm{pH} 7.2$ with $\mathrm{KOH}$. The bath solution contained the following (in mM): $129 \mathrm{NaCl}, 1.25 \mathrm{NaH}_{2} \mathrm{PO}_{4}$, $1.8 \mathrm{MgSO}_{4}, 1.6 \mathrm{CaCl}_{2}, 3 \mathrm{KCl}, 10 \mathrm{Na}-\mathrm{HEPES}$, and 5 glucose, pH 7.4 with $\mathrm{NaOH} .{ }^{16}$
Recordings were carried out after the exposure of the cell cultures for 1,4 , and $24 \mathrm{~h}$ to mApoE-PA-LIPs at $10 \mu \mathrm{M}$ concentration or for $4 \mathrm{~h}$ with LIPs functionalized only with PA (PA-LIPs) or only with mApoE (mApoE-LIPs), at $10 \mu \mathrm{M}$ concentration. To study the effect of the presence of $A \beta$ in the culture, cells were exposed to $\mathrm{A} \beta 500 \mathrm{nM}$ for 2, 4, or $8 \mathrm{~h}$. To evaluate the efficacy of the liposome treatment in presence of $A \beta$, we incubated the neurons with oligomers $500 \mathrm{nM}$ for $8 \mathrm{~h}$, the last four of which were in coincubation with $10 \mu \mathrm{M}$ of mApoE-PA-LIPs. To note, LIPs and A $\beta$ were not applied during the recording phase of the experiments; thus, any change observed raised from the pretreatment performed before the cell culture dish was transferred to the electrophysiological recording setup. ${ }^{17}$

\section{Statistical analyses}

Data are presented as mean \pm SEM. Statistical analyses were conducted using OriginPro 8 software (OriginLab Corporation, Northampton, MA, USA). Group comparisons were made with unpaired Student's $t$-test. An ANOVA was performed for multiple comparison, followed by Fisher correction. $p$-Values of $\leq 0.05$ were considered significant $(*)$.

\section{Results}

\section{Characterization of mApoE-PA-LIP}

In the present study, we utilized the previously described mApoE-PA-LIPs and PA-LIPs as a control. Size, polydispersity, and $\zeta$-potential values are reported in Figure 1A.

\begin{tabular}{llll} 
& & & \\
\cline { 2 - 4 } Liposomes (LIP) & Diameter $(\mathbf{n m} \pm \mathbf{S D})$ & PDI & $\zeta$-potential $(\mathbf{m V} \pm \mathbf{S D})$ \\
\hline PA-LIP & $112.6 \pm 4$ & 0.099 & $-27.38 \pm 1.32$ \\
mApoE-PA-LIP & $128.4 \pm 7$ & 0.113 & $-21.49 \pm 1.75$ \\
\hline
\end{tabular}
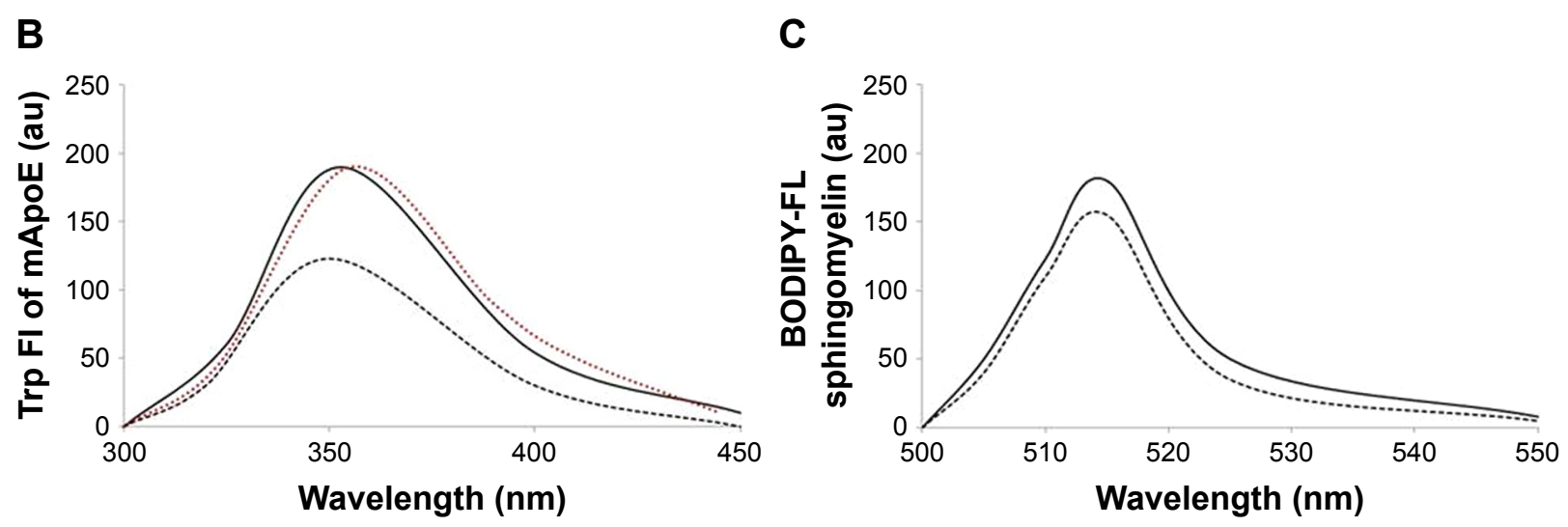

Figure I Characterization of LIPs.

Notes: (A) Size, polydispersity, and $\zeta$-potential values of PA-LIPs and mApoE-PA-LIPs determined by dynamic light scattering and interferometic Doppler velocimetry. (B) Fluorescent spectra of Trp-mApoE peptide in solution (red line), after incubation with LIPs (dark line) or after mApoE-PA-LIPs purification (dark dotted line). (C) Fluorescent spectra of BODIPY-FL CI2-sphingomyelin embedded in LIPs before $(-)$ and after purification ( $\bullet \cdot)$.

Abbreviations: LIPs, liposomes; PA, phosphatidic acid. 
Table I Biocompatibility of PA-LIPs and mApoE-PA-LIPs

\begin{tabular}{llll}
\hline LIPs & $\begin{array}{l}\text { Exposure } \\
\text { time (h) }\end{array}$ & $\begin{array}{l}\text { LDH release } \\
\mathbf{( \% )}\end{array}$ & $\begin{array}{l}\text { Reduction in MTT } \\
\text { cleavage (\%) }\end{array}$ \\
\hline Untreated & 4 & $0 \pm 3.5$ & $0 \pm 1.12$ \\
mApoE-PA-LIPs & 4 & $0.5 \pm 2.1(p=0.5)$ & $3.2 \pm 1.3(p=0.2)$ \\
Untreated & 48 & $0 \pm 1.5$ & $0 \pm 1.4$ \\
mApoE-PA-LIPs & 48 & $0.14 \pm I(p=0.6)$ & $4 \pm 0.5(p=0.3)$ \\
\hline
\end{tabular}

Notes: The release of LDH represents a sign of membrane damage, while the reduction in the cleavage of MTT to obtain formazan is an index of a decrease in the metabolic activity. Results (presented as mean $\pm \mathrm{SE}$ ) are representative for three independent experiments ( $n=4$ for each experiment); $p$-value is calculated vs non-treated cells.

Abbreviations: PA, phosphatidic acid; LIPs, liposomes; LDH, lactate dehydrogenase.

LIPs had a size below $200 \mathrm{~nm}$ diameter, low polydispersity index (PDI), and a negative $\zeta$-potential indicating that dispersion was homogeneous in terms of dimension and was electrically stabilized. The yield of LIP surface functionalization with $\mathrm{mApoE}$ peptide, followed by measuring the blue shift of Trp present in the peptide sequence, was $65 \% \pm 12 \%$ (Figure $1 \mathrm{~B}$ ), and the recovery of BODIPY-FL C12-Sm after LIP purification was $88.4 \% \pm 9 \%$ (Figure $1 \mathrm{C}$ ) vs a total lipid recovery $>90 \%$.

\section{Biocompatibility and internalization}

Primary cultures of neural cells from neonatal rats were exposed to mApoE-PA-LIPs for 4 or $48 \mathrm{~h}$ at a concentration of $10 \mu \mathrm{M}$ (untreated cells as control). When comparing LIPs-treated and untreated cells, LDH assay displayed a maximum of $1 \%$ of plasma membrane distress and MTT assay a $7 \%$ of decrease in the metabolic activity (Table 1). These results indicated non-significant changes in plasma membrane integrity and metabolic stress, respectively, thus a high degree of biocompatibility.

NPs internalization is a common phenomenon in in vitro experiments; thus, confocal laser scanning microscopy was used to observe whether fluorescent mApoE-PA-LIPs were internalized by neural cells. The images acquired after $1 \mathrm{~h}$ of incubation revealed no particles inside the cytoplasm of neither neurons (specifically labeled with anti- $\beta$ III tubulin antibody; Figure 2A upper panel) nor astrocytes (labeled with GFAP antibody, Figure 2B upper panel). As the incubation time was extended up to 4 and $24 \mathrm{~h}$, the status of LIPs aggregation increased, and, again, the fluorescence was localized in the proximity of the cell plasmamembrane and not inside the cells (Figure 2A and B, lower panels). These qualitative data strongly suggested that neural cells did not uptake mApoEPA-LIPs independently from the duration of their exposure.

\section{mApoE-PA-LIPs incubation increased neuron excitability}

Since mApoE-PA-LIPs are specific NPs designed to overcome the BBB, all experiments presented from now on were conducted in order to evaluate the effects of the incubation of neurons with these given LIPs for different time intervals (1, 4, and $24 \mathrm{~h})$. mApo-LIPs and PA-LIPs incubation was evaluated as a further control only when significant differences were observed in comparison to untreated cells.

Using the patch-clamp technique, we measured the passive membrane properties of neurons, such as cellular capacitance and input resistance, the resting membrane
A
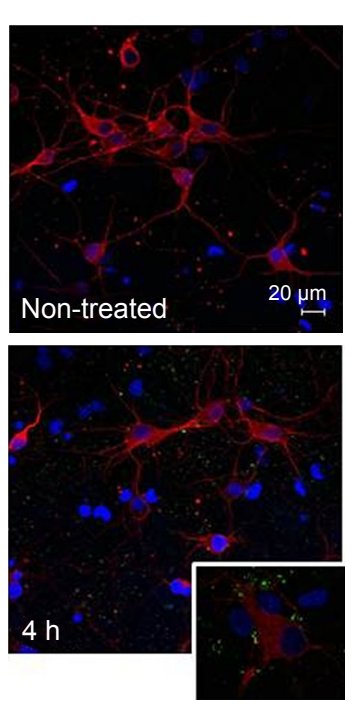
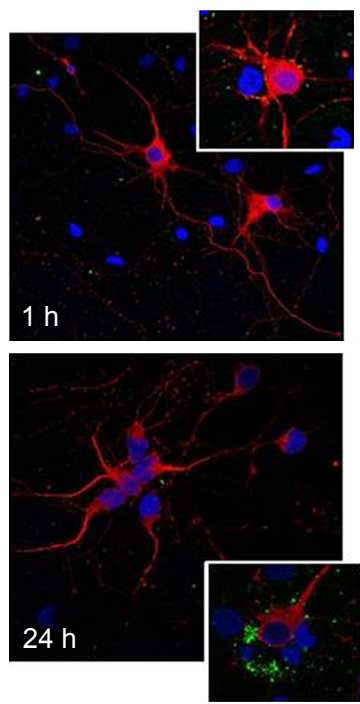

B
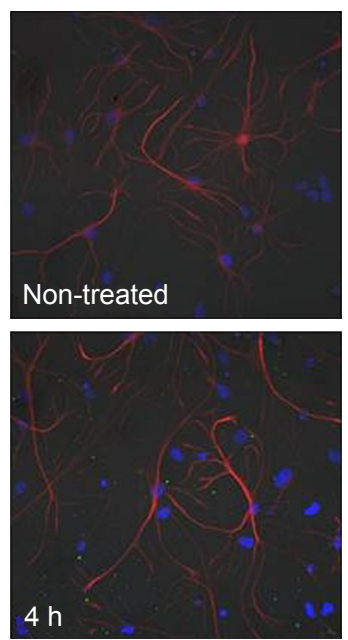
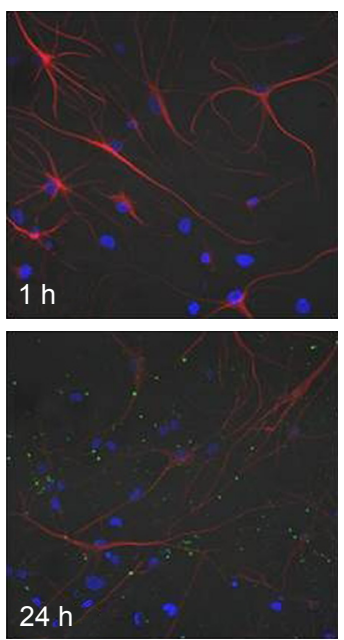

Figure 2 Confocal images of primary cultures of neuronal cells incubated with mApoE-PA-LIPs at different incubation time.

Notes: (A) Anti- $\beta$ III tubulin antibody specifically marks neuronal cells, while (B) GFAP antibody specifically marks glial cells. Neural cultures were either non-treated or incubated with fluorescent mApoE-PA-LIPs for I, 4, and $24 \mathrm{~h}$. Images revealed that liposomes were not internalized by neurons (A) nor by glial cells (B).

Abbreviations: PA, phosphatidic acid; LIPs, liposomes; GFAP, glial fibrillary acidic protein. 
potential, the rheobase current for AP generation, and the firing frequencies against the amplitude of injected current.

Following the treatment with mApoE-PA-LIPs, cell capacitance and cell resting membrane potential did not change; however, the input resistance significantly increased by $17 \%$ in neurons incubated for $4 \mathrm{~h}$ with mApoE-PA-LIPs, even though an increasing trend was also present when the incubation lasted for just $1 \mathrm{~h}$. Cells exposed for the same period with PA-LIPs did not show any change, while a 13\% increase was observed in cells incubated with mApoE-LIPs. All these data are summarized in Table 2 .

The minimum current necessary to elicit an AP averaged at $25.9 \pm 2 \mathrm{pA}$ in untreated cells. In neurons treated with mApoE-PA-LIPs, this parameter was overall smaller; in particular, after $4 \mathrm{~h}$ of incubation, two cellular populations were clearly distinguishable: in about half of the cells $(51 \%, 26$ cells out of 51), the rheobase current averaged at $30.4 \pm 4 \mathrm{pA}$, while in the remaining fraction $(49 \%, 25$ cells out of 51$)$, the rheobase current averaged at $20.4 \pm 2 \mathrm{pA}(p<0.01)$. A very similar distribution was observed for the $\mathrm{mApoE}$-LIPs incubated neurons $(27.5 \pm 5 \mathrm{pA}, \mathrm{n}=40$ and $18.06 \pm 4 \mathrm{pA}, \mathrm{n}=31$, $p<0.01)$. In the other conditions tested, all the cells started to fire when the injected current amplitude was similar to the one of the untreated cells $(25.4 \pm 4,33.3 \pm 4$, and $28.6 \pm 5$ for cells incubated with mApoE-PA-LIPs for 1 or $24 \mathrm{~h}$ and with PA-LIPs for $4 \mathrm{~h}$, respectively; Table 2). Figure $3 \mathrm{~A}$ shows representative trains of APs recorded in neurons either untreated (top) or treated with mApoE-PA-LIPs (center and bottom). Again, the analysis of the firing frequency revealed the coexistence of two different behaviors in neurons incubated for 1 or $4 \mathrm{~h}$ with mApoE-PA-LIPs almost at all the amplitude of current steps injected (Figure 3B). In particular, 43 and $58 \%$ of cells incubated for 1 and $4 \mathrm{~h}$, respectively, exhibited a significantly higher (almost twofold) firing frequency, while in the remaining cells analyzed, the firing rate was similar to the one of untreated neurons (Figure 3C for the scattered data at $4 \mathrm{~h}$ of incubation). When the incubation was prolonged up to $24 \mathrm{~h}$, the measured firing rate was no longer affected by the treatment.

As an example, at $60 \mathrm{pA}$ of injected current, the untreated cells showed a frequency of firing of $15.9 \pm 1.4 \mathrm{~Hz}(\mathrm{n}=60)$; in the population of neurons incubated with mApoE-PA-LIPs for $1 \mathrm{~h}$, nine out of 16 cells $(56.3 \%)$ fired at $17.1 \pm 2.4 \mathrm{~Hz}$, while the remaining seven cells (43.7\%) fired at $28.9 \pm 1.3 \mathrm{~Hz}$ $(p<0.01)$. After $4 \mathrm{~h}$ of incubation with mApoE-PA-LIPs, $42 \%$ of cells $(\mathrm{n}=16)$ exhibited a frequency of $13.3 \pm 1.2 \mathrm{~Hz}$ and the remaining $58 \%(\mathrm{n}=22)$ fired twice as frequently, reaching $25.3 \pm 1.5 \mathrm{~Hz}(p<0.01$, Figure $3 \mathrm{C})$. In neurons treated for $4 \mathrm{~h}$ with mApoE-LIPs we observed a similar behavior, with $46 \%$ of cells ( 26 out of 57 ) firing at $13.7 \pm 1.4 \mathrm{~Hz}$ and $54 \%$ (31 cells) firing at $23.7 \pm 0.5 \mathrm{~Hz}(p<0.01)$. In PA-LIPs, the firing frequency was $16.3 \pm 2.2 \mathrm{~Hz}$ in $100 \%$ of cells $(n=15)$.

To unravel the reason behind the coexistence of populations of cells firing at different frequencies, we observed the distribution of the fluorescent nanoliposomes on the neural cells cultures under similar conditions of those used for patch-clamp experiments. The differences in these live imaging pictures compared with the ones obtained with the immunofluorescence protocol (Figure 2) are related to the fact that the former samples were treated with a much more delicate approach, as described in the "Materials and methods" section, that did not include several strong washes. Figure 4A shows that while some cells were indeed in contact with mApoE-PA-LIPs (green arrows), some were not (white arrows). As well, the fluorescent spots (ie, mApoE-PA-LIPs) over the culture layer significantly increased their dimension with time, being $214 \pm 63,403 \pm 153$, and $1,125 \pm 488 \mathrm{~nm}$ at 1 , 4 , or $24 \mathrm{~h}$ of incubation, respectively (Figure 4B). Moreover, the amount of cells having $\mathrm{mApoE}-\mathrm{PA}$-LIPs adherent to their surface was higher after 1 or $4 \mathrm{~h}$ of incubation and decrease

Table 2 Passive membrane properties and other parameters measured in untreated neurons or in neurons incubated with LIPs

\begin{tabular}{|c|c|c|c|c|c|c|}
\hline & $\begin{array}{l}\text { Untreated } \\
(n=73)\end{array}$ & $\begin{array}{l}\text { mApoE-PA-LIPs } \\
(I \mathrm{~h})(\mathrm{n}=\mid 7)\end{array}$ & $\begin{array}{l}\text { mApoE-PA-LIPs } \\
(4 \mathrm{~h})(\mathrm{n}=5 \mathrm{I})\end{array}$ & $\begin{array}{l}\text { mApoE-PA-LIPs } \\
(24 \text { h) }(n=9)\end{array}$ & $\begin{array}{l}\text { PA-LIPs } \\
(4 \mathrm{~h})(n=15)\end{array}$ & $\begin{array}{l}\text { mApoE-LIPs } \\
(4 \mathrm{~h})(\mathrm{n}=7 \mathrm{I})\end{array}$ \\
\hline Cell capacitance $(\mathrm{pF})$ & $24.89 \pm 2$ & $27.89 \pm 2$ & $27.18 \pm 2$ & $29.95 \pm 3$ & $30.67 \pm 4$ & $24.40 \pm 2$ \\
\hline Resting potential $(\mathrm{mV})$ & $-45.25 \pm 2$ & $-47.67 \pm 4$ & $-45.46 \pm 2$ & $-45.01 \pm 2$ & $-50.20 \pm 3$ & $-49.5 I \pm 3$ \\
\hline Input resistance $(M \Omega)$ & $704 \pm 58$ & $821.71 \pm 103$ & $822 \pm 102(p=0.04)$ & $661.79 \pm 108$ & $638.72 \pm 77$ & $795 \pm 126(p=0.04)$ \\
\hline Rheobase current $(\mathrm{pA})$ & $25.9 \pm 2$ & $25.4 \pm 4$ & $\begin{array}{l}30.4 \pm 4(n=25) \\
20.4 \pm 2(n=26) \\
(p<0.01)\end{array}$ & $33.3 \pm 4$ & $28.6 \pm 5$ & $\begin{array}{l}27.5 \pm 5(n=40) \\
I 8.06 \pm 4(n=3 I) \\
(p<0.01)\end{array}$ \\
\hline
\end{tabular}

Notes: Data are presented as mean \pm SEM and are representative of at least three independent experiments. In the inset, an image of a typical neuron under patch-clamp experiment.

Abbreviations: LIPs, liposomes; PA, phosphatidic acid; SEM, standard error of the mean. 
A
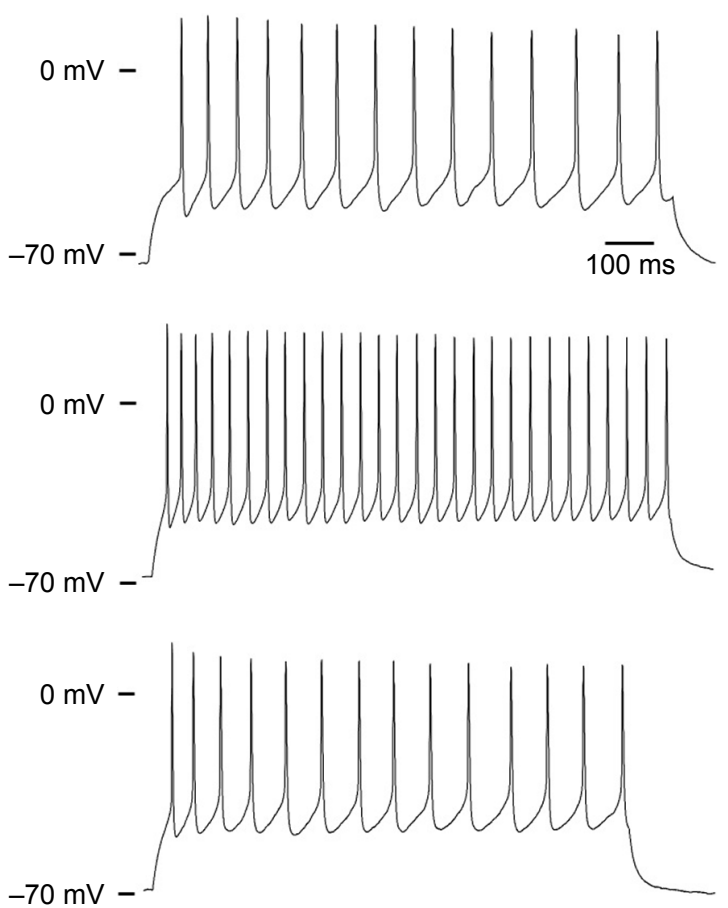

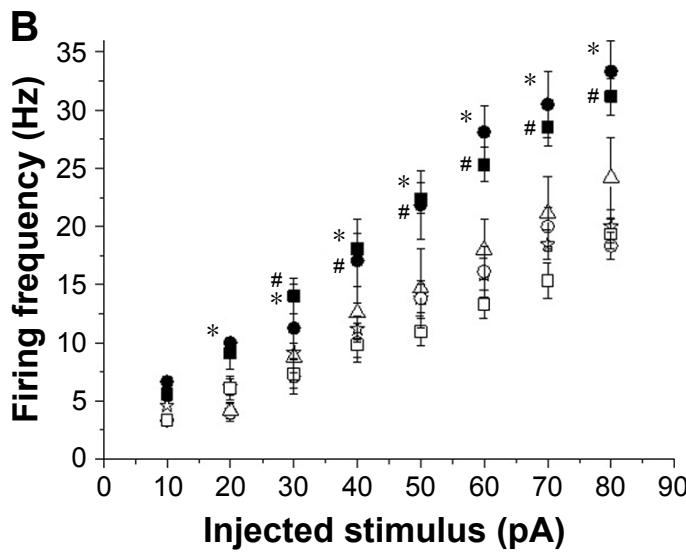

岤 Untreated $(\mathrm{n}=60)$

O 1 h similar to untreated $(n=8)$

- $1 \mathrm{~h}(\mathrm{n}=9)$

$\square 4 \mathrm{~h}$ similar to untreated $(n=16)$

$4 \mathrm{~h}(\mathrm{n}=22)$

$\triangle 24 h(n=10)$

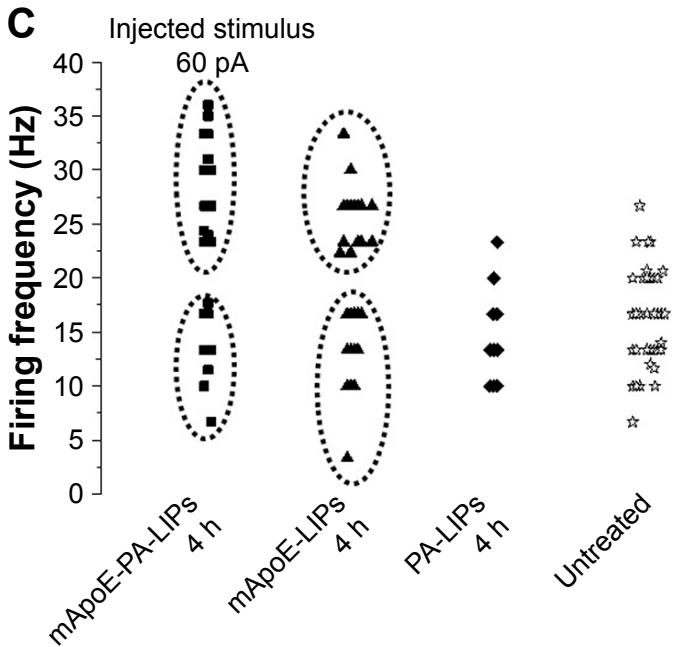

Figure 3 Effect of mApoE-PA-LIPs on the firing frequency of neurons.

Notes: (A) Representative current-clamp recordings from neurons; APs were recorded during the application of I s of depolarizing injected current of 60 pA from a holding potential of $-70 \mathrm{mV}$. The upper traces were recorded from untreated cells, the middle and the bottom traces were recorded from cells incubated with mApoE-LIPS for $4 \mathrm{~h}$. The difference in the frequency of firing is evident. (B) Relationship between the average frequency of AP firing elicited and the respective amplitude of injected stimulus over the whole range of stimuli tested. Neurons incubated with mApoE-PA-LIPs for I h $(n=17)$ or $4 \mathrm{~h}(\mathrm{n}=38)$ displayed sub-population of cells that fired with a significantly higher frequency (filled circles and squares, respectively) compared to control condition ( $n=60$; empty star) or to longer time incubations ( $n=10$; empty triangles) $(*, \# p<0.0 \mathrm{I})$. For the sake of clarity of the plot, data related to the mApoE-LIPs incubation are not presented in this panel. (C) Scattered plot showing the existence of two populations of firing frequency in neurons incubated for $4 \mathrm{~h}$ with mApoE-PA-LIPs or mApoE-LIPs when the injected current was $60 \mathrm{pA}$. Untreated neurons and neurons incubated with PA-LIPs behaved similarly among themselves.

Abbreviations: PA, phosphatidic acid; LIPs, liposomes; AP, action potential.

at $24 \mathrm{~h}$; in fact, the number of fluorescent events counted per field with time was $9.78 \pm 1.01,8.2 \pm 0.46$ and $5.8 \pm 0.5$ at 1,4 or $24 \mathrm{~h}$ of incubation, respectively (Figure 4C). Unfortunately, for technical reasons, we could not perform patch-clamp experiments using fluorescent mApoE-PA-LIPs.

\section{Effects of $A \beta$ oligomers incubation or $A \beta$ oligomers and mApoE-PA-LIPs co-incubation on neuron properties}

In order to study the properties of neurons in presence of amyloid beta, we incubated the neural cultures with $500 \mathrm{nM}$ of $\mathrm{A} \beta$ oligomers for 2,4 , and $8 \mathrm{~h}$. The treatment had no effect on the neuronal resting membrane potential $(-43.85 \pm 4 \mathrm{mV}$, $2 \mathrm{~h}, \mathrm{n}=5 ;-42.21 \pm 8 \mathrm{mV}, 4 \mathrm{~h}, \mathrm{n}=18$; and $-46.2 \pm 5 \mathrm{mV}, 8 \mathrm{~h}$, $\mathrm{n}=15)$, on the cell input resistance $(996 \pm 32 \mathrm{M} \Omega, 2 \mathrm{~h}, \mathrm{n}=4$; $806 \pm 167 \mathrm{M} \Omega, 4 \mathrm{~h}, \mathrm{n}=15$; and $834 \pm 164 \mathrm{M} \Omega, 8 \mathrm{~h}, \mathrm{n}=13$ ), on the rheobase current $(27.3 \pm 3 \mathrm{pA}, 2 \mathrm{~h}, \mathrm{n}=4 ; 29.5 \pm 10 \mathrm{pA}, 4 \mathrm{~h}$, $\mathrm{n}=19$; and $23.6 \pm 7 \mathrm{pA}, 8 \mathrm{~h}, \mathrm{n}=14$ ), and on the frequency of firing $(16.6 \pm 4 \mathrm{~Hz}, 2 \mathrm{~h}, \mathrm{n}=3 ; 15.5 \pm 5 \mathrm{~Hz}, 4 \mathrm{~h}, \mathrm{n}=6$; and $12.5 \pm 4$, $8 \mathrm{~h}, \mathrm{n}=8$ ) (Figure 5A-D). At last, in order to test the efficacy of mApoE-PA-LIP on neuronal excitability in presence of $A \beta$ in the culture, after $4 \mathrm{~h}$ of incubation with the oligomers, 
A

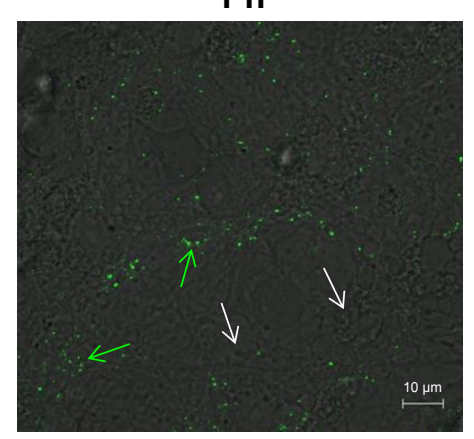

B

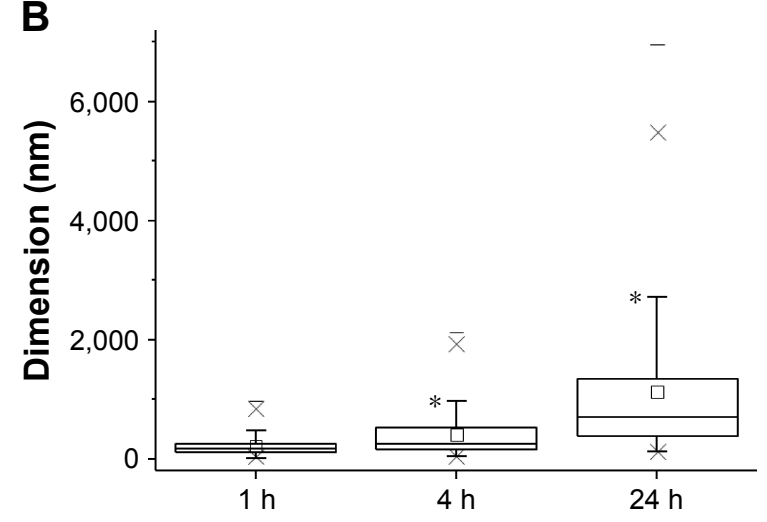

$4 \mathrm{~h}$

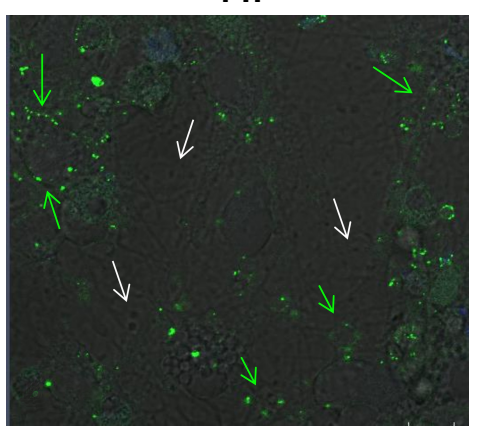

$24 \mathrm{~h}$

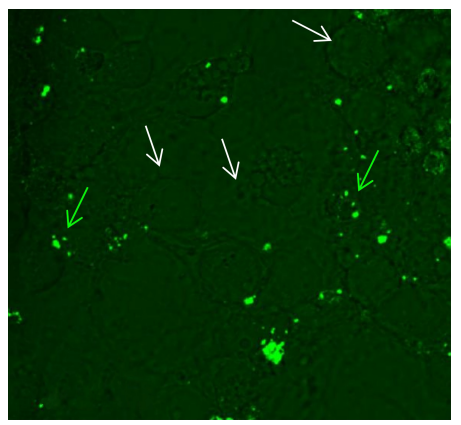

C

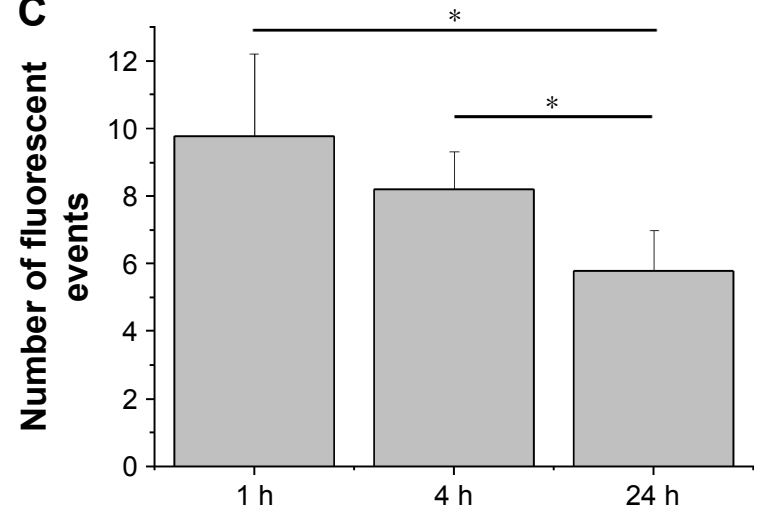

Figure 4 Fluorescence imaging on live cells.

Notes: (A) Distribution of the fluorescent mApoE-PA-LIPs on the neuronal cell cultures after I h (left), $4 \mathrm{~h}$ (central), or $24 \mathrm{~h}$ (right) of incubation. Green and white arrows, respectively, indicate cells interacting and non-interacting with mApoE-PA-LIPs. (B) Box-chart showing the dimension of the green fluorescent spots corresponding to mApoE-PA-LIPs in the cell culture. The size increased over time (*significance versus the dimension at I h of incubation; $p<0.0 \mathrm{I})$. (C) Bar graph counting, on average, the fluorescent events found in each field analyzed.

Abbreviations: PA, phosphatidic acid; LIPs, liposomes.

mApoE-PA-LIPs were added for $4 \mathrm{~h}$ (ie, $4 \mathrm{~h}$ of incubation of $A \beta$ alone plus $4 \mathrm{~h}$ of coincubation of $A \beta$ and mApoEPA-LIPs). Under this condition, the cell resting membrane potential, the input resistance, and the rheobase current measured did not change significantly $(-49.3 \pm 3 \mathrm{mV}[\mathrm{n}=9]$, $902 \pm 141 \mathrm{M} \Omega[\mathrm{n}=8]$ and $18.7 \pm 4 \mathrm{pA}[\mathrm{n}=8]$, respectively). Interestingly, though, concerning the frequency of firing, we could still point out the presence of two populations of neurons: one firing at $15 \pm 1 \mathrm{~Hz}(\mathrm{n}=4)$ and another composed by two cells at 23.3 and $26.7 \mathrm{~Hz}$, respectively (Figure 5D).

\section{Discussion}

The main obstacles to the development of potential therapeutic approaches for neurodegenerative diseases are the anatomical and physiological organization of the BBB, which is a weir of endothelial cells surrounding the capillaries of the CNS, preventing the passage of almost all pharmaceuticals and, thus, protecting the brain.

In the past few years, it has been proven that appropriately functionalized NPs are able to cross the BBB, therefore representing a potential diagnostic and therapeutic tool of considerable impact in neurodegenerative disorders. In this context, a prominent place is certainly occupied by NPs developed for the treatment of $\mathrm{AD}$, one of the most common causes of dementia in the world. AD is responsible for a progressive and irreversible loss of neuronal cells that, in turn, involves the manifestation and the sharpening of cognitive, behavioral, and physical deficits.

Several studies have previously suggested that mApoEPA-LIPs could potentially be advantageously used with regard to $A D$ as they proved to reduce the $A \beta$ burden in mouse animal models of the disease and to prevent memory impairment in a model of presymptomatic stage of $\mathrm{AD} .{ }^{6,7}$ This capability is likely attributable to the presence, on their surface, of PA molecules conferring the ability to bind $A \beta$ with high affinity ${ }^{2}$ and of the peptide containing the receptorbinding sequence of ApoE, improving their transport through the BBB. ${ }^{13}$

In the present study, we evaluated the effects of these double functionalized LIPs on primary cultures of cortical 

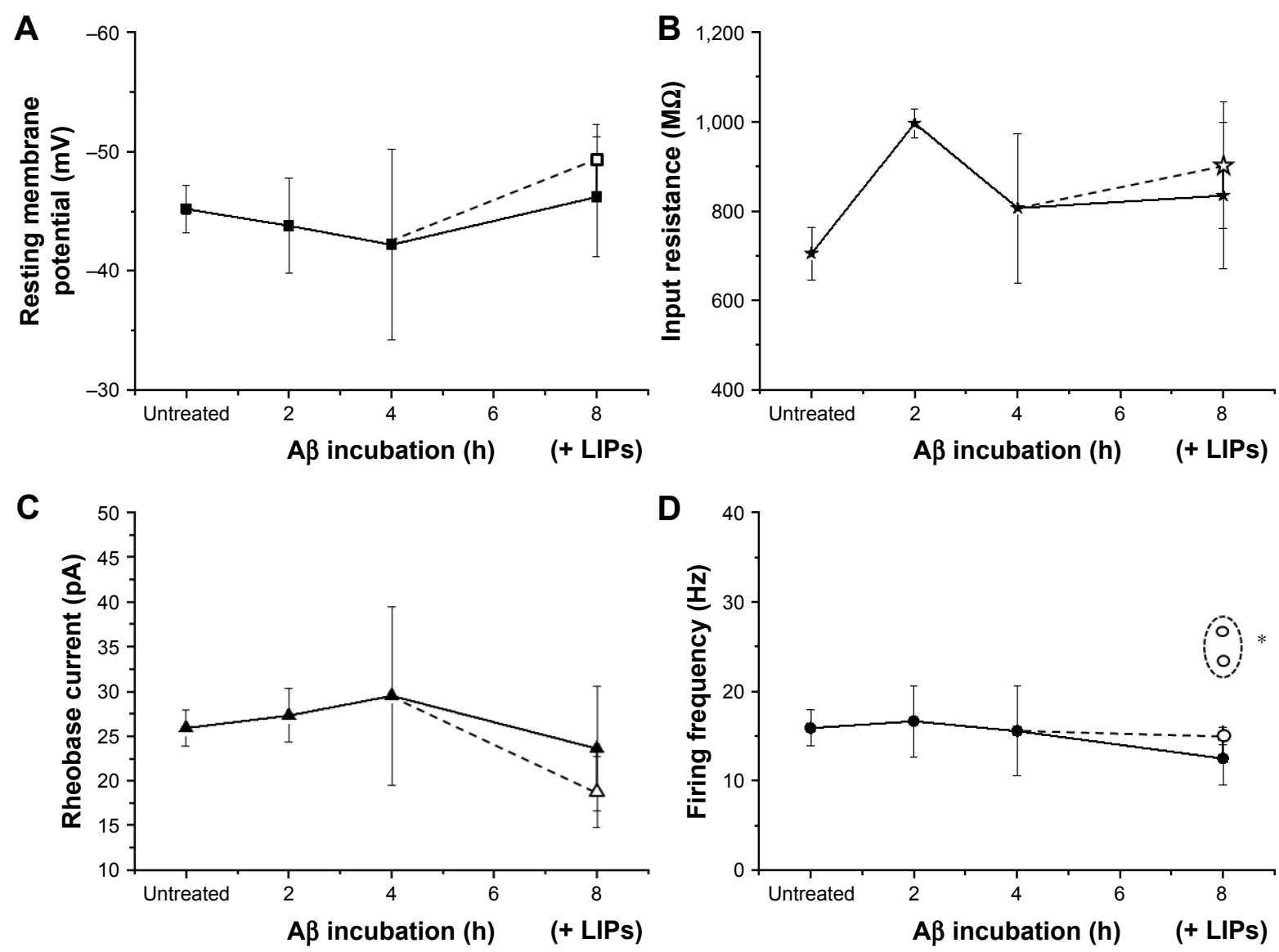

Figure 5 Effects of $A \beta$ oligomers or $A \beta$ oligomers and mApoE-PA-LIPs coincubation on neuron properties.

Notes: Panels represent the resting membrane potential $(\mathbf{A})$, the cell input resistance (B), the rheobase current (C), and the firing frequency (D) in untreated neurons and in neurons incubated with $A \beta$ oligomers for 2,4 , or $8 \mathrm{~h}$ (data connected with the straight line). The empty symbols represent the same parameters measured after $4 \mathrm{~h}$ of $A \beta$ incubation alone followed by $4 \mathrm{~h}$ of coincubation with $A \beta$ plus mApoE-PA-LIPs. (D) The empty circles are reported as averaged value of four out of six cells firing as the untreated ones, while the two empty circles in the dashed profile represent the subpopulation of neurons (two out of six) firing at a significantly higher frequency $\left({ }^{*} p<0.0 \mathrm{I}\right)$. Abbreviations: $A \beta, \beta$-amyloid peptide; PA, phosphatidic acid; LIPs, liposomes.

neural cells isolated from neonatal rats with a particular attention to the neuron electrophysiological activity.

Previous results demonstrated the biocompatibility of mApoE-PA-LIPs on hCMEC/D3 cells, ${ }^{3}$ on HUVEC cells and on macrophages RAW264.7. ${ }^{18}$ Our data demonstrated that mApoE-PA-LIPs were biocompatible also with neural cells, as we did not detect signs of distress neither on the plasmamembrane (LDH release) nor on the metabolic activity (MTT production) for up to $48 \mathrm{~h}$ of incubation. This is an important result considering that $\mathrm{mApoE}$-PA-LIPs role is likely to disaggregate and bind $\mathrm{A} \beta$ within the brain parenchyma.

Interestingly and differently to what has been previously observed in other cellular systems, ${ }^{3}$ these LIPs were not internalized in neurons nor in astrocytes. Low-density lipoprotein receptor (LDLR) and LDLR-related protein 1 (LRP1) are the main metabolic receptors for lipoproteins in the brain, the first being mainly expressed in the astrocytes and the latter most expressed in neurons and in particular in cortical neurons of neonatal rats. ${ }^{19}$ Upon binding ApoE, LDLR and LRP1 form endocytotic vesicles to transport their ligands from the cell surface to intracellular compartments. ${ }^{20}$ From our data, the internalization of the mApoE-PA-LIPs was prevented in neural cells. As already stated, LIPs used in this study exhibit the motif constituted by residues $141-150$ of human apolipoprotein E. This motif possesses the conserved lysines and arginines crucial for the interaction between ApoE and LDLRs and subsequent nanoliposome internalization in endothelial cells. ${ }^{3}$ Studies, not related to NPs, showed that in fibroblasts, the minimal sequence of ApoE recognized by the receptor has to be bound to lipoprotein in order to allow the internalization of the complex ligandreceptor, ${ }^{21}$ and in HepG2 cells, it has to be linked to a class A amphipathic peptide. ${ }^{22} \mathrm{Up}$ to now, there is no information regarding the internalization of the complex ligand-receptor in neurons, when only the minimal sequence of ApoE is present for the binding. Indeed the VLDL receptor does not 
require the association of ApoE with lipids for recognition and binding, whereas the LRPR prefers lipid-bound forms of ApoE..$^{23}$ In order to unravel the reason why LIPs are not internalized by neurons, one may incubate these cells with a series of synthetic sequences of ApoE of different length to study if there are specific requirements in the apolipoprotein E sequence for the internalization in this system. Yet, this is far beyond the goal of this paper.

The study of the electrical properties of the cells after mApoE-PA-LIPs incubation showed no changes in neuronal cell capacitance, but a significant increase in their input resistance. Considering that mApoE-PA-LIPs are primarily composed of lipids, that in electrical terms represent elements increasing the membrane electrical isolation, we can hypothesize that if LIPs were not fused with the cell membrane (as Figures 2 and 5 suggest), they only adhered or promoted a minor plasmalemmal lipids incorporation, thus justifying the lack of the effects on the capacitance of the cell. This may however bring to either a redistribution of charge along the surface of the membrane of the excitable cells and thus the resistance may be altered ${ }^{24,25}$ or a direct effect of the lipids on the ion channels gating. In fact, while neutral lipids (ie, phosphatidylethanolamine, phosphatidylcholine) have little effect on channel activity, lipids with highly negatively charged head groups (ie, PA) strongly modulate ion channels. ${ }^{26}$ Data obtained incubating neurons with mApoE-PA-LIPs were comparable with those obtained with mApoE-LIPs (thus without PA and its negatively charged head groups) leaning toward the first hypothesis. Moreover, we hypothesize that the reason why cells exposed to PA-LIPs did not show any change in input resistance compared to mApoE-PA-LIPs is related to the fact that without $\mathrm{mApoE}$, the liposome may not stick to the cell membrane.

The value of the resting membrane potential was not different after incubation of neurons with mApoE-PA-LIPs, while the rheobase current decreased significantly, coherently with the increase in the input resistance. The same results were obtained when the incubation was done with mApoE-LIPs.

In terms of firing frequency, in neurons incubated with mApoE-PA-LIPs (as well as with mApoE-LIPs) for a period up to $4 \mathrm{~h}$, we could identify two different populations: one population that fired like the untreated cells and a second population that fired at twice that frequency. Longer incubation periods resulted in the disappearance of this latter population of cells. Taking advantage of the live fluorescence images, we can speculate that the mApoE-PA-LIPs dispersed in the culture medium had the (static) chance to interact with cultured neurons. But, over time, they aggregate as evidenced by the increase in the area of the single fluorescent spot. By aggregating, the number of objects available to interact with the cells decreased, as demonstrated by the number of fluorescent events counted per field, making the interaction less probable, thus detectable. From the data shown, it seems that the ideal time to observe the interaction phenomenon and its consequences on neurons is between 1 and $4 \mathrm{~h}$ of incubation. At $24 \mathrm{~h}$, the aggregation phenomenon seized the LIPs limiting the number of the neuron-mApoE-PA-LIPs interaction events; and in fact, after $24 \mathrm{~h}$ of incubation with mApoE-PALIPs, the effect on firing rate was not distinguishable from that of the untreated or PA-LIPs treated neurons.

Overall, the results obtained after the incubation of neurons with mApoE-PA-LIPs were very similar to the ones gathered after mApoE-LIPs incubation, suggesting that $\mathrm{mApoE}$ peptide is mainly responsible for the changes observed in the electrical properties of the cells.

Since $\mathrm{AD}$ implies the presence of $\mathrm{A} \beta$ oligomers and plaques in the brain, it would be interesting to have the possibility to investigate the efficacy of mApoE-PA-LIPs on the electrical properties of neurons isolated from an $\mathrm{AD}$ model. The literature reports few studies in which this topic was investigated in vivo, ${ }^{27}$ or in hippocampal slices, or in primary hippocampal neurons from neonatal mice. ${ }^{17,28}$ Results demonstrated a hyperactivity in terms of calcium release ${ }^{27}$ and in the increase in the firing frequency of APs evoked in response to current steps ${ }^{28}$ leaving many basic intrinsic neuronal properties unaltered. ${ }^{17,28}$ Indeed, the isolation of cortical neurons from adult rats or mice is not easily feasible. In the literature, there is only one paper aiming at developing a method for preparing isolated cells of medial vestibular nucleus (MVN) from adult mice, which however remain viable only for 3 days in culture. ${ }^{29}$ These cells, however, are not consistent with our model. Moreover, in order to study the electrical properties of isolated neurons, embryonic or neonatal animals are preferred for culturing. For these reasons, we mimicked the $\mathrm{AD}$ model, treating the primary neural cultures with $A \beta$ oligomers ${ }^{17}$ for increasing time of incubation. Consistent with previous results, ${ }^{17,28}$ also in our study, $A \beta$ did not induce changes in the passive properties of neurons, and also the firing frequency remained stable, as reported previously. ${ }^{17}$ The reason why we did not detect hyperactivity in neurons incubated with $A \beta$ may simply rely in the fact that we recorded APs in single cells and not in brain slices. Moreover, the strategy we used for the incubation is a balance between a reasonable time to allow $A \beta$ to produce its effects and the inevitable decline that it produces with the inevitable decline on cell viability that it produces with time, 
which may not allow patch-clamp experiments to be performed at all. It is worthy of note, however, that after the incubation with $\mathrm{A} \beta$ alone followed by $4 \mathrm{~h}$ of co-incubation of $\mathrm{A} \beta$ plus mApoE-PA-LIPs, we could still detect a fraction ( 2 cells out of 6) of the neurons firing at higher frequency compared to the neurons incubated for $8 \mathrm{~h}$ only with $A \beta$, suggesting that the efficacy of mApoE-PA-LIPs is maintained even in presence of the oligomers.

\section{Conclusion}

The most relevant results concerning the effect of the incubation of neurons with mApoE-PA-LIPs were the transient increase in the input resistance and the decrease of the rheobase current, consistent with an ultimately transient increase in neuronal excitability. In particular, a higher input resistance means that less synaptic input (or current injection) is necessary to lead to larger voltage changes, as the decrease in the rheobase current confirmed. Thus, changes in input resistance can change the responsiveness of the neurons to other inputs. This adjustment in intrinsic excitability is usually at the basis of plasticity of the response of the membrane of excitable neurons acting as a metaplasticity mechanism by lowering the threshold for synaptic changes. ${ }^{30}$

Metaplasticity develops as a result of a series of timedependent events: an initial priming event (eg, LIPs adhesion) induces physiological or biochemical changes in neurons that can modulate plasticity induced by a subsequent event (eg, electrical stimulation); these changes may have an impact, for example, in the enhanced ability of an excitatory postsynaptic potential (EPSP) to generate an AP, again, as proved by the decrease in the rheobase current found. ${ }^{31}$

Modulation of intrinsic excitability may act as an adjustable gain control mechanism and have consequences for the integration processes.

Aging-related deficits in learning have been linked to failure to modulate intrinsic excitability, in the sense that a reduced intrinsic excitability may be an important predictor of cognitive decline; with this in mind, we may argue that an increase in intrinsic excitability, as we found after the incubation of neurons with mApoE-PA-LIPs, may be a predictor of cognitive preservation.

However, since the changes in intrinsic plasticity were transient, we cannot say that they code for the memory itself, but this transient enhancement of excitability may promote processes that allow successful memory formation and that facilitate acquisition of new learning.

It is well known that alterations in intrinsic properties of neuronal membranes are regarded as an important mechanism involved in the abnormal excitability of cortical circuitry and possibly account for the susceptibility to initiation and spread of seizures..$^{30,32,33}$ Nevertheless, in a previous study where mice were treated with mAPO-PA-LIPs for 7 months and observed for 3 more months, ${ }^{7}$ no seizure-related behaviors such as immobility, compulsive spitting, alteration in locomotor activity, social relationships, and reactivity to environmental stimuli ${ }^{34}$ were observed.

LIPs and, in particular, mApoE-PA-LIPs have great potential in biotechnology and medicine, in particular in the treatment of AD. Some of the initial concerns regarding their possible toxicity have been widely alleviated by the demonstration of their biocompatibility in several cellular models as well as in primary neural cultures. Their ability to reduce $\mathrm{A} \beta$ accumulation in the brain ${ }^{6}$ brought us to investigate their effect on electrical properties of neurons, given their proximity when passing the BBB. Data presented here, besides adding some relevant information on the lack of LIPs internalization by neuronal cells, indicate that treatment with mApoE-PA-LIPs transiently increases neuronal excitability and suggests the basis for the interpretation of the cognitive recovery found in previous work. ${ }^{7}$ The modulation of the intrinsic excitability could be an important factor in the search for neurobiological approaches to mitigate or prevent the onset of aging-related cognitive impairments and even rescue those deficits after they emerge.

\section{Acknowledgment}

The research leading to these results has received funding from the European Community's Seventh Framework Programme (FP7/2007-2013) under grant agreement no 212043.

\section{Author contributions}

Anna Binda performed the patch clamp and immunofluorescence experiments and analyzed the data. Alice Panariti performed the biocompatibility experiments and analyzed the data. Andrea Barbuti designed the patch clamp experiments and participated in the drafting of the manuscript. Carmen Murano set up the cell culture. Roberta Dal Magro synthetized the liposomes and $\mathrm{A} \beta$ oligomers. Massimo Masserini participated in the drafting of the manuscript. Francesca Re synthetized the liposomes, performed their characterization and participated in the drafting of the manuscript. Ilaria Rivolta coordinated the study, designed the patch clamp experiments, analyzed the data and participated in the drafting of the manuscript. All authors contributed toward data analysis, drafting and revising the paper and agree to be accountable for all aspects of the work. 


\section{Disclosure}

The author reports no conflicts of interest in this work.

\section{References}

1. Parveen S, Misra R, Sahoo SK. Nanoparticles: a boon to drug delivery, therapeutics, diagnostics and imaging. Nanomedicine. 2012; $8(2): 147-166$.

2. Gobbi M, Re F, Canovi M, et al. Lipid-based nanoparticles with high binding affinity for amyloid-beta1-42 peptide. Biomaterials. 2010; 31(25):6519-6529.

3. Bana L, Minniti S, Salvati E, et al. Liposomes bi-functionalized with phosphatidic acid and an ApoE-derived peptide affect $A \beta$ aggregation features and cross the blood-brain-barrier: implications for therapy of Alzheimer disease. Nanomedicine. 2014;10(7):1583-1590.

4. Conti E, Gregori M, Radice I, et al. Multifunctional liposomes interact with Abeta in human biological fluids: Therapeutic implications for Alzheimer's disease. Neurochem Int. 2017;108:60-65.

5. Bhaskar S, Tian F, Stoeger T, et al. Multifunctional nanocarriers for diagnostics, drug delivery and targeted treatment across blood-brain barrier: perspectives on tracking and neuroimaging. Part Fibre Toxicol. 2010;7:3.

6. Balducci C, Mancini S, Minniti S, et al. Multifunctional liposomes reduce brain $\beta$-amyloid burden and ameliorate memory impairment in Alzheimer's disease mouse models. J Neurosci. 2014;34(42):14022-14031.

7. Mancini S, Balducci C, Micotti E, et al. Multifunctional liposomes delay phenotype progression and prevent memory impairment in a presymptomatic stage mouse model of Alzheimer disease. J Control Release. 2017;258:121-129.

8. Panariti A, Miserocchi G, Rivolta I. The effect of nanoparticle uptake on cellular behavior: disrupting or enabling functions? Nanotechnol Sci Appl. 2012;5:87-100.

9. Warren AE, Payne CK. Cellular binding of nanoparticles disrupts the membrane potential. RSC Adv. 2015;5(18):13660-13666.

10. Sosan A, Svistunenko D, Straltsova D, et al. Engineered silver nanoparticles are sensed at the plasma membrane and dramatically modify the physiology of Arabidopsis thaliana plants. Plant J. 2016;85(2):245-257.

11. Cestèle S, Scalmani P, Rusconi R, Terragni B, Franceschetti S, Mantegazza M. Self-limited hyperexcitability: functional effect of a familial hemiplegic migraine mutation of the Nav1.1 (SCN1A) Na+ channel. J Neurosci. 2008;28(29):7273-7283.

12. Re F, Cambianica I, Zona C, et al. Functionalization of liposomes with ApoE-derived peptides at different density affects cellular uptake and drug transport across a blood-brain barrier model. Nanomedicine. 2011;7(5):551-559.

13. Re F, Cambianica I, Sesana S, et al. Functionalization with ApoEderived peptides enhances the interaction with brain capillary endothelial cells of nanoliposomes binding amyloid-beta peptide. J Biotechnol. 2010;156(4):341-346.

14. Mancini S, Minniti S, Gregori $M$, et al. The hunt for brain A $\beta$ oligomers by peripherally circulating multi-functional nanoparticles: potential therapeutic approach for Alzheimer disease. Nanomedicine. 2016;12(1):43-52.

15. Panariti A, Lettiero B, Alexandrescu R, et al. Dynamic investigation of interaction of biocompatible iron oxide nanoparticles with epithelial cells for biomedical applications. J Biomed Nanotechnol. 2013;9(9):1556-1569.

16. DiFrancesco JC, Barbuti A, Milanesi R, et al. Recessive loss-of-function mutation in the pacemaker HCN2 channel causing increased neuronal excitability in a patient with idiopathic generalized epilepsy. J Neurosci. 2011;31(48):17327-17337.
17. Tamagnini F, Scullion S, Brown JT, Randall AD. Intrinsic excitability changes induced by acute treatment of hippocampal CA1 pyramidal neurons with exogenous amyloid $\beta$ peptide. Hippocampus. 2015; 25(7):786-797.

18. Orlando A, Re F, Sesana S, et al. Effect of nanoparticles binding $\beta$-amyloid peptide on nitric oxide production by cultured endothelial cells and macrophages. Int J Nanomedicine. 2013;8:1335-1347.

19. Fan QW, Iosbe I, Asou H, Yanagisawa K, Michikawa M. Expression and regulation of apolipoprotein e receptors in the cells of the central nervous system in culture: a review. J Am Aging Assoc. 2001;24(1):1-10.

20. $\mathrm{Bu}$ G. Apolipoprotein $\mathrm{E}$ and its receptors in Alzheimer's disease: pathways, pathogenesis and therapy. Nat Rev Neurosci. 2009;10(5): 333-344.

21. Mims MP, Darnule AT, Tovar RW, et al. A nonexchangeable apolipoprotein E peptide that mediates binding to the low density lipoprotein receptor. J Biol Chem. 1994;269(32):20539-20547.

22. Datta G, Garber DW, Chung BH, et al. Cationic domain 141-150 of apoE covalently linked to a class A amphipathic helix enhances atherogenic lipoprotein metabolism in vitro and in vivo. J Lipid Res. 2001;42(6):959-966.

23. Ruiz J, Kouiavskaia D, Migliorini M, et al. The apoE isoform binding properties of the VLDL receptor reveal marked differences from LRP and the LDL receptor. J Lipid Res. 2005;46(8):1721-1731.

24. Curtis ASG, Chandler C, Picton N. Cell surface lipids and adhesion. J Cell Sci. 1975;8:375-378.

25. Murray D, Arbuzova A, Hangyás-Mihályné G, et al. Electrostatic properties of membranes containing acidic lipids and adsorbed basic peptides: theory and experiment. Biophys J. 1999;77(6):3176-3188.

26. Tucker SJ, Baukrowitz T. How highly charged anionic lipids bind and regulate ion channels. J Gen Physiol. 2008;13(5):431-438.

27. Busche MA, Grienberger C, Keskin AD, et al. Decreased amyloid- $\beta$ and increased neuronal hyperactivity by immunotherapy in Alzheimer's models. Nat Neurosci. 2015;18(12):1725-1727.

28. Scala F, Fusco S, Ripoli $C$, et al. Intraneuronal $A \beta$ accumulation induces hippocampal neuron hyperexcitability through A-type $\mathrm{K}(+)$ current inhibition mediated by activation of caspases and GSK-3. Neurobiol Aging. 2015;36(2):886-900.

29. Him A, Altuntaş S, Öztürk G, Erdoğan E, Cengiz N. Isolation and culture of adult mouse vestibular nucleus neurons. Turk J Med Sci. 2017; 47(6):1903-1911.

30. Lasoń W, Chlebicka M, Rejdak K. Research advances in basic mechanisms of seizures and antiepileptic drug action. Pharmacol Rep. 2013;65(4):787-801.

31. Sehgal M, Song C, Ehlers VL, Moyer JR Jr. Learning to learn - intrinsic plasticity as a metaplasticity mechanism for memory formation. Neurobiol Learn Mem. 2013;105:186-199.

32. Zhang L, Liang Z, Zhu P, et al. Altered intrinsic properties and bursting activities of neurons in layer IV of somatosensory cortex from Fmr-1 knockout mice. Exp Neurol. 2016;280:60-69.

33. Meisel C, Schulze-Bonhage A, Freestone D, Cook MJ, Achermann P, Plenz D. Intrinsic excitability measures track antiepileptic drug action and uncover increasing/decreasing excitability over the wake/sleep cycle. Proc Natl Acad Sci U S A. 2015;112(47):14694-14699.

34. Heinrichs SC, Seyfried TN. Behavioral seizure correlates in animal models of epilepsy: a road map for assay selection, data interpretation, and the search for causal mechanisms. Epilepsy Behav. 2006;8(1): $5-38$. 
International Journal of Nanomedicine

Dovepress

\section{Publish your work in this journal}

The International Journal of Nanomedicine is an international, peerreviewed journal focusing on the application of nanotechnology in diagnostics, therapeutics, and drug delivery systems throughou the biomedical field. This journal is indexed on PubMed Central, MedLine, CAS, SciSearch ${ }^{\circledR}$, Current Contents ${ }^{\circledR} /$ Clinical Medicine,
Journal Citation Reports/Science Edition, EMBase, Scopus and the Elsevier Bibliographic databases. The manuscript management system is completely online and includes a very quick and fair peer-review system, which is all easy to use. Visit http://www.dovepress.com/ testimonials.php to read real quotes from published authors.

Submit your manuscript here: http://www.dovepress.com/international-journal-of-nanomedicine-journal 